\title{
The Content Analysis of Pb in Representative Green Belts Plants on Major Traffic Road of Zhenzhou City
}

\author{
Hairong Gao ${ }^{1, a}$, Jianjun Chen ${ }^{1, b}$, Jie Zhang ${ }^{2, c}$ \\ ${ }^{1}$ College of Chemistry and Chemical Engineering, Zhengzhou Normal University, Zhengzhou, \\ China \\ ${ }^{2}$ College of Physics and Electronic Engineering, Zhengzhou Normal University, Zhengzhou,China \\ aemail: gaohairong2004@163.com, bemail: Barclon312165854@qq.com, \\ 'email: jiezhang76@qq.com
}

\begin{abstract}
Keywords: Analysis; Pb; plant leaf; Zhenzhou city; traffic road.
Abstract. To investigate the pollution situation of $\mathrm{Pb}$ in Zhengzhou city and obtain high bioaccumulation green plants, the $\mathrm{Pb}$ contents of plants leaves from the green belts on major traffic roads in Zhenzhou city, were analyzed by using graphite furnace atomic absorption spectrometry . The results showed that $\mathrm{Pb}$ content in different plants was distrinct, which ranged from $0.16 \mathrm{mg} \cdot \mathrm{Kg}^{-1}$ to 7.65 $\mathrm{mg} \cdot \mathrm{Kg}^{-1}$. Meanwhile, the accumulation capacity of different spatial plants on the same sampling point was also significantly different, The order was the lawn plants $>$ the shrubs $>$ the trees. Besides, the results showed that the content of $\mathrm{Pb}$ in different tissue with the same plant was distrinct: $\mathrm{R}$. chinensis flower was about 5 times of R. chinensis leaf; Among all the tested plants, accumulation capacity of $\mathrm{Pb}$ in Platanus orientalis Linn., Ligustrum vicaryi, Trifolium repens L. and R. chinensis flower was the largest.Therefore, they are expected to used as multilevel biopurification model for repairing $\mathrm{Pb}$ pollution.
\end{abstract}

\section{Introduction}

With the rapid development of economy and automobile industry in China, $\mathrm{Pb}$ pollution problem has become a threat to human health as "invisible killer", which can damage human health [1]. Road greening belts can not only beautify the urban environment, but also has good purification effect for urban air pollutants [2]. Studies have shown that green plants greening belts can clear heavy metal pollution of the roadside soil and the atmosphere, it can effectively reduce the degree of pollution of the environment $[3,4]$. Therfore, plant kinds will be very important to biological purification and bioremediation. In our work, $\mathrm{Pb}$ content of 13 kinds of green plants such as trees, shrub and grass on the main traffic roads green belts in zhengzhou city were analyzed in order to get high $\mathrm{Pb}$ bioaccumulation plants. The experimental data will provide theoretical basis for the selection of green plants to repair $\mathrm{Pb}$ pollution.

\section{Materials and methods}

Field plot. Selected plants were growing in green belts of traffic roads in zhengzhou city, where was the central plains region in Henan province. Plant leaves were selected from eight different areas .

Plant sample. Old plant leaves of bioaccumulation balance were picked from growing well plants near bus roadside, according to the method of "S" shape points .Each plant randomly were selected 10 strains, gathering the dispersion of a piece of putting blade 10 to 20 . The total representative greening plants were 13 kinds, which were respectively three trees (Platanus orientalis Linn., Populus L. and willows Salix babylonica), seven kinds of shrubs (photinia xfraseri, Sabina chinensis (L.) Ant. cv. Aurea, Nandina domestica., Ligustrum quihoui Carr., Berberis thunbergii, Ligustrum vicaryi, ilex purpurea Hassk and R. chinensis leaf ), Two lawn plants (Trifolium repens L. and Trifolium pratense L.), a kind of flower (R. chinensis flower). 
Analytical procedures. Plant sample processing method was as the reference literature [5], but was adjusted according to the optimized experiment. Specific operation was below, plant leaves were dried to constant weight in the oven with $100{ }^{\circ} \mathrm{C}$ after they were washed by using secondary deionized water. Quartering sampling was used after they were broken. $1.0000 \mathrm{~g}$ sample was accurately weighed and transfered into a triangle conical flask. After placed for the whole night with glass covering, Then each sample was added $5 \mathrm{~mL}$ concentrated nitric acid and was heated $0.5 \mathrm{~h}$ with $100{ }^{\circ} \mathrm{C}$ on the electric heating furnace of heating, then $10 \mathrm{~mL} \mathrm{HNO}_{3}-\mathrm{HClO}_{4}(\mathrm{~V} / \mathrm{V}=3: 1)$ was added to the sample and heated about $1 \mathrm{~h}$ with $200{ }^{\circ} \mathrm{C}, 3$ drops of hydrogen peroxide was dropped to digest completely until thick white smoke was produced with nearly dry. After cooling the sample was transfered into $50 \mathrm{~mL}$ volumetric flask and diluted to scale with $0.2 \%$ dilute nitric acid. Some samples was appropriately diluted according to the linear range when they were determined.

Instrumental analysis and Quantitation. $\mathrm{Pb}$ content of plant samples were determined by graphite furnace atomic absorption spectrometry. The working conditions of the spectrometer as follows: 283.3 $\mathrm{nm}$ wavelength, spectral band width is $0.4 \mathrm{~nm}, 2$ malamp current, argon Ar as shielding gas, deuterium lamp deducting background. Graphite furnace temperature program are shown in Table 1. Quantitative data were obtained by the standard curve, which was drawed with working liquid configuration respectively $0 \mathrm{ng} \cdot \mathrm{mL}^{-1}, 10 \mathrm{ng} \cdot \mathrm{mL}^{-1}, 20 \mathrm{ng} \cdot \mathrm{mL}^{-1}, 30 \mathrm{ng} \cdot \mathrm{mL}^{-1}, 40 \mathrm{ng} \cdot \mathrm{mL}^{-1}, 50 \mathrm{ng} \cdot \mathrm{mL}^{-1}$ standard solution, the linear regression equation $A=0.0028+0.0020 C\left(R^{2}=0.9941\right)$.

Table1. Graphite furnace temperature program

\begin{tabular}{ccccc}
\hline procedure & $\begin{array}{c}\text { temperature } \\
\left({ }^{\circ} \mathrm{C}\right)\end{array}$ & $\begin{array}{c}\text { heating time } \\
(\mathrm{s})\end{array}$ & $\begin{array}{c}\text { keeping time } \\
(\mathrm{s})\end{array}$ & $\begin{array}{c}\text { gas flow } \\
(\mathrm{L} / \mathrm{min})\end{array}$ \\
\hline dry & 110 & 5 & 15 & 0.4 \\
ashing & 350 & 10 & 15 & 0.4 \\
atomization & 1800 & 0 & 3 & 0 \\
purification & 1900 & 1 & 2 & 0.4 \\
\hline
\end{tabular}

\section{Results and discussion}

Contrast of $\mathbf{P b}$ content from different areas. To analyze $\mathrm{Pb}$ pollution status of different areas in zhengzhou city, Platanus orientalis Linn. blades were obtained from eight sampling sites according to distribution characteristics of the greening plant.The results ( Fig.1) showed that the content of $\mathrm{Pb}$ in the leaves ranged from $0.17 \mathrm{mg} . \mathrm{Kg}^{-1}$ to $1.25 \mathrm{mg} . \mathrm{Kg}^{-1}$, with a mean of $0.57 \mathrm{mg}$. $\mathrm{Kg}^{-1}$. Wang [6] reported that average content of $\mathrm{Pb}$ in plants leaves was $17.416 \mathrm{mg}^{-\mathrm{Kg}^{-1}}$ in ShenYang steets, Shao [7] determined that $\mathrm{Pb}$ content of plant leaves in the main streets of ChangChun city, ranging from 8.20 mg. $\mathrm{Kg}^{-1} \sim 58.50 \mathrm{mg} . \mathrm{Kg}^{-1}$, with a mean of $19.7 \mathrm{mg} . \mathrm{Kg}^{-1}$. Compared with the results of the ChangChun and ShenYang, $\mathrm{Pb}$ pollution level in the plants on both sides of the main bus routes in ZhengZhou city was not high. This may be attributed to less large industrial factories, mines and regulatory environmental measures in ZhengZhou.

It is generally believed that the heavy metal content in plant leaf can reflect the surrounding environment pollution, which provide important data for environmental quality assessment and pollution repair [8]. Our research results showed $\mathrm{Pb}$ content of the same plants was obvious different in different areas. Thereinto, $\mathrm{Pb}$ pollution was the most serious on North ring road and Culture road intersection with $1.25 \mathrm{mg} . \mathrm{Kg}^{-1}$, where $\mathrm{Pb}$ content of plant leaves was 7.35 times the ones on Zhengzhou university south gate station. It is near carrefour shopping mall and the entry of the viaduct, where serious traffic congestion and bus stopping for a long time caused more emissions. Therefore, high content of $\mathrm{Pb}$ was probably associated with higher vehicle emissions.

Contrast of $\mathrm{Pb}$ content in different green plants. In environmental remediation, trees are very important due to its big adsorption characteristics. Three trees (Platanus orientalis Linn., Populus L. and willows Salix babylonica) from four different sites were analyzed to figure out bioaccumulation capability of different greening trees. The results were shown in Fig.2. Bioaccumulation capability of 
$\mathrm{Pb}$ in the three trees were a little different. The order was Platanus orientalis Linn. > Populus L. > Salix babylonica .

In order to study the spatial distribution of $\mathrm{Pb}$ pollution ,different spatial plants blades from Garden road and Guo-ji intersection were selected to detected $\mathrm{Pb}$ content. In the experiment, 9 kinds of greening plant blades were selected to compare the bioaccumulation capability to $\mathrm{Pb}$. The data (Fig.3) showed that the bioaccumulation capability of $\mathrm{Pb}$ in 9 kinds plant was very different. The order is Trifolium repens L. >Ligustrum vicaryi > Trifolium pratense L. > Ligustrum quihoui Carr. >Sabina chinensis (L.) Ant. cv. Aurea >photinia $\times$ fraseri $>$ Berberis thunbergii >ilex purpurea Hassk $>$ Platanus orientalis Linn. Besides, the plants from different spatial distribution had different bioaccumulation capacity. The whole trend was lawn plants $>$ shrubs $>$ trees; we also found that the Bioaccumulation capacity of difference shrubs was different. For example, bioaccumulation content of Ligustrum vicaryi blades was up to $6.86 \mathrm{mg} \cdot \mathrm{Kg}^{-1}$, and ilex purpurea Hassk was as low as $1.30 \mathrm{mg} . \mathrm{Kg}^{-1}$. Besides, the bioaccumulation ability in different organizations with the same plant had significantly different , For example, $\mathrm{Pb}$ content in $\mathrm{R}$. chinensis flower from four different sampling sites(Fig.4) was respectively $7.65 \mathrm{mg} . \mathrm{Kg}^{-1}, 6.84 \mathrm{mg} . \mathrm{Kg}^{-1}, 4.76 \mathrm{mg} . \mathrm{Kg}^{-1}$ and $4.21 \mathrm{mg} \cdot \mathrm{Kg}^{-1}$, while the corresponding $\mathrm{Pb}$ content $\mathrm{R}$. chinensis leaf was $1.56 \mathrm{mg} . \mathrm{Kg}^{-1}, 2.43 \mathrm{mg} \cdot \mathrm{Kg}^{-1}, 1.24 \mathrm{mg} \cdot \mathrm{Kg}^{-1}$ and $1.73 \mathrm{mg} . \mathrm{Kg}^{-1}, \mathrm{~Pb}$ content in R. chinensis flower was about $4 \sim 5$ times $\mathrm{Pb}$ content of leaf. Bioaccumulation capacity of lawn plants were stronger than other kinds of plants, $\mathrm{Pb}$ content of Trifolium pratense $\mathrm{L}$. and Trifolium repens L. was respectively $7.32 \mathrm{mg} . \mathrm{Kg}^{-1}$ and $6.15 \mathrm{mg} \cdot \mathrm{Kg}^{-1}$. Bioaccumulation capacity of arbor plants was respectively weaker, the $\mathrm{Pb}$ content of platane sample was the lowest $\left(0.91 \mathrm{mg} \cdot \mathrm{Kg}^{-1}\right)$.

As a new technique developed in recent years, bioremediation has been widely used in repair heavy metal pollution due to its low cost, easy operation and greenization. The use of plants as resources for phytoremediation is one of the effective methods to remove heavy metal pollution[9]. Therefore, the selection of highway greening plant is an important environmental governance. Our research showed that R. chinensis flower, Trifolium repens L. and Ligustrum vicaryi had strong bioaccu- mulation capacity to $\mathrm{Pb}$. They not only have strong purification ability, but also can beautify the living environment, which can be widely applied in urban green belts. Besides, Ligustrum vicary expected to replace ilex purpurea Hassk in green belts, owing toits higher adsorption capacity and colorful.

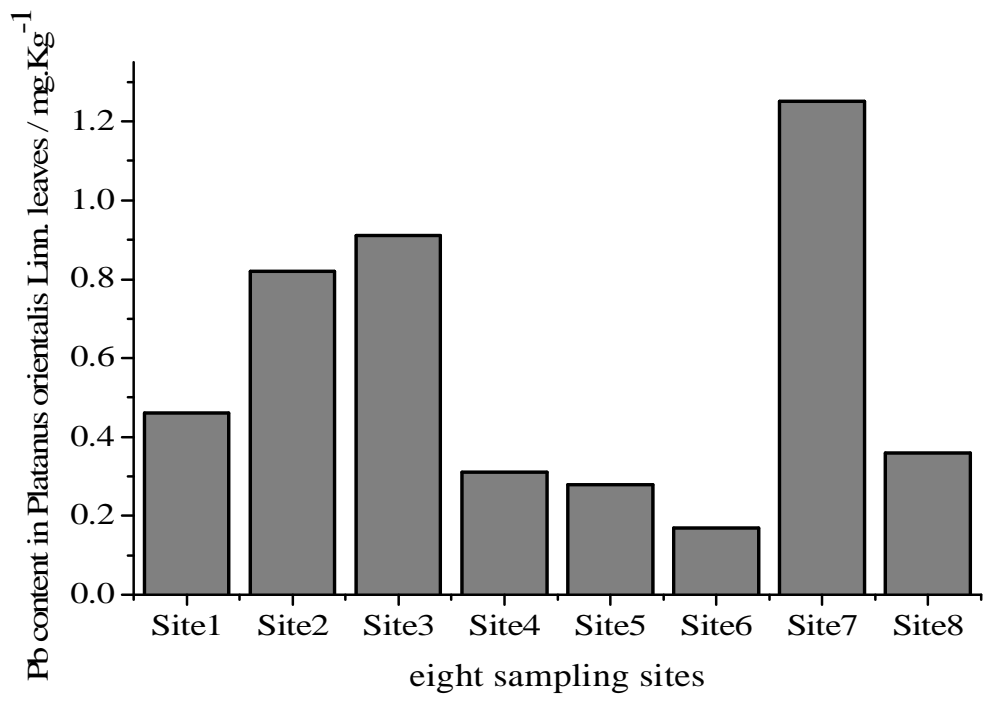

Fig.1 Pb content of platane(Platanus orientalis Linn.) leaves on eight sampling sites (refer with: Fig. 1, Site1: The seventh middle school station on San-quan road, Site2: Culture road and Lian-huo highway intersection, Site3: Garden road and Guo-ji intersection, Site4: Liu-lin station on garden road, Site5: Ying-cai treet station on Culture road, Site6: Zhengzhou university south gate station, Site7: North ring road and Culture road intersection, Site8: Dong-feng channel station on Garden road) 


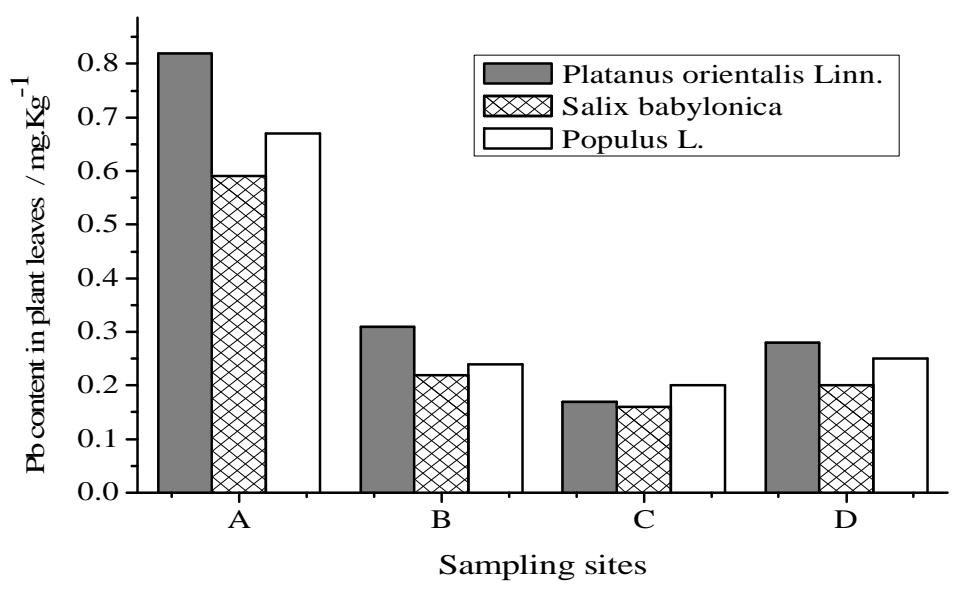

Fig.2 Contrast of $\mathrm{Pb}$ bioaccumulation capability in three kinds of trees

(refer with: Fig. 2, A: Culture road and Lian-huo highway intersection, B: Liu-lin station on garden road , C: Zhengzhou university south gate station, D: Ying-cai treet station on culture road)

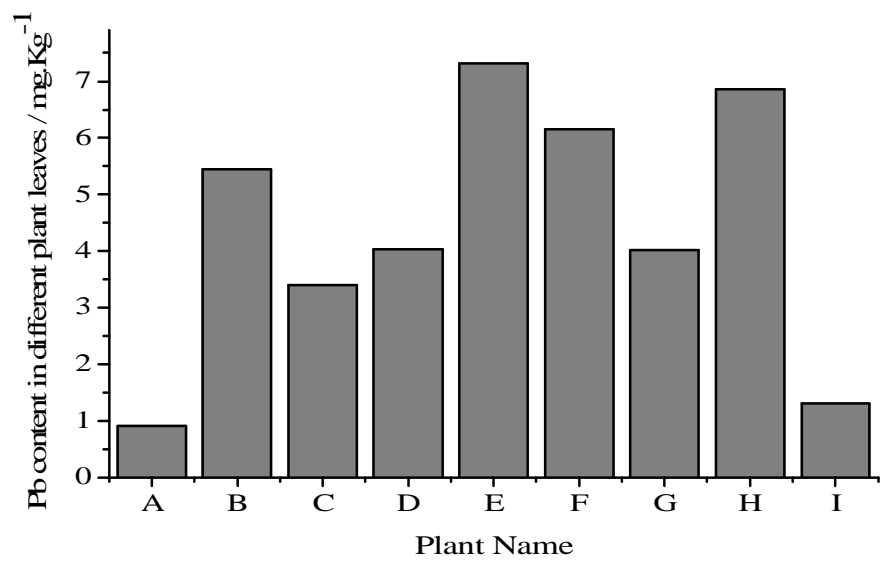

Fig.3 Contrast of bioaccumulation capability of different plants from the same sampling site (refer with: Fig. 3, A: Platanus orientalisLinn., B: photinia xfraseri, C: Sabina chinensis (L.), D: Ligustrum quihoui Carr.,E: Trifolium repens L., F: Trifolium pratense L., G: Berberis thunbergii, H: Ligustrum vicaryi, I: ilex purpurea Hassk)

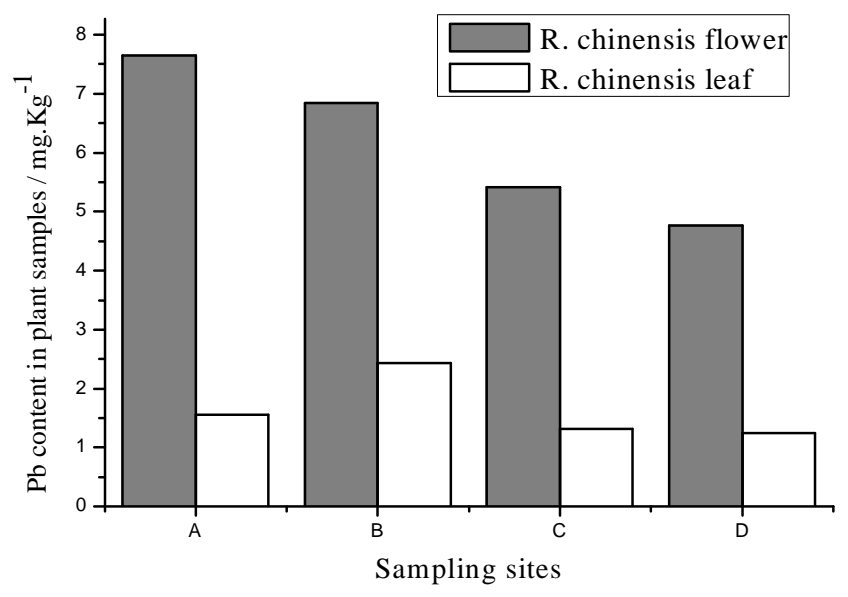

Fig.4 Contrast of bioaccumulation capability of $\mathbf{R}$. chinensis flower and leaf

(refer with: Fig. 4, A: The seventh middle school station on San-quan road, B: Culture road and Lian-huo highway intersection, C: Liu-lin station on garden road, D: Ying-cai treet station on Culture road) 


\section{Conclusion}

The content of $\mathrm{Pb}$ in the 13 green plants in zhengzhou city showed that all plant leaves had a certain bioaccumulation quantity to lead due to atmospheric pollution. Compared with other cities reported in literatures in China, Zhenzhou city's pollution level is relatively lower. The lead content in plant leaves ranged from $0.16 \mathrm{mg} \cdot \mathrm{Kg}^{-1} \sim 7.65 \mathrm{mg} \cdot \mathrm{Kg}^{-1}$.

From screening plant view, R. chinensis flower, Trifolium repens L. and Ligustrum vicaryi can be suitful for repairing $\mathrm{Pb}$ pollution in air. In order to balance the needs of urban plant diversity and space purifying effect, the appropriate plants with high metal absorption capacity of different spatial distribution (arbor, shrub, lawn plants) should be selected. Alhough Bioaccumulation capacity of arbor plants is relative weaker, the potential of its environmental pollution repair was not allowed to ignore due to its high biomass and strong adaptability.

\section{Acknowledgements}

This work was financially supported by the key scientific research project of universities in henan province (15A15008420) in China.

\section{References}

[1] B. He, Z.J. Yun and J.B. Shi: Chin. Sci. Bull. Vol. 58 (2013), p. 134

[2] D.M. Zheng, Q.C. Wang and N Zheng: J. Environ. Sci. Vol. 28 (2007), p. 189

[3] Y.R. Xu, Z.W. Feng and C.X. Wang: Hubei Agri. Sci. Vol. 21 (2002), p. 75

[4] Z.Y. Du, S.J. Xing and Y.M. Song: J. Soil and Water Conserv Vol. 21 (2007), p. 175

[5] X.H. Liu, Y.T. Gao and K. Sardar: J. Environ. Sci. Vol. 20 (2008), p. 1469

[6] C.M. Wang and R.N. Wang: Ecol. Environ. Sci. Vol. 18 (2009), p. 1307

[7] Z.Q. Shao, C.L. Li and S. Wang: Environ. Sci. and Management Vol. 35 (2010), p. 114

[8] Mj.G. Archer and R.A Caldwell: Water Air Soil Poll Vol. 157 (2004), p. 257

[9] W.S. Shu, Z.H. Ye and C.Y. Lan: Environ Pollut Vol. 120 (2002), p. 445 